\title{
ELES ERAM MUITOS RUFFATOS/CAVALOS: A CIDADE DE SÃO PAULO E A EMERGÊNCIA DE UM ESCRITOR A PARTIR DO ROMANCE ELES ERAM MUITOS CAVALOS
}

Renato Kleibson da Silva ${ }^{1}$

\section{INTRODUÇÃO}

A obra ficcional do escritor mineiro Luiz Ruffato (Cataguases, 1963) interessa, sobretudo, aos que buscam entender o Brasil contemporâneo a partir da trajetória da pequena burguesia operária dos grandes centros urbanos do país. A contemporânea sociologia do trabalho brasileira chama esse segmento de "precariado" ou "ralé", uma classe até então não protagonista da prosa produzida no país.

Antes de começar a sua pentalogia sobre o operariado urbano brasileiro com a série Inferno Provisório, que narra a trajetória dessa classe social, cada vez mais numerosa a partir do decênio de 1950 até 2000 (arco temporal da série), no Brasil, portanto, cada livro cobrindo uma década, L. Ruffato lançou em 2001 o seu romance de estreia, Eles eram muitos cavalos².

Com Eles eram muitos cavalos (EEMC), L. Ruffato abre um espaço na prosa contemporânea produzida no Brasil para o tema do proletariado urbano. Podemos ressaltar que EEMC percorre um caminho poucas vezes trilhado pela prosa nacional: abordar o proletariado urbano que começou a imigrar massivamente para os grandes centros urbanos do país, sobretudo para o eixo Rio-São Paulo, a partir dos anos 1950.

Talvez O cortiço (1890), de Aloísio Azevedo (São Luís, 1857-1913), seja o primeiro empreendimento literário que visou apresentar esse estrato da população brasileira, ainda no século XIX. Porém, retratou-o em uma chave naturalista, em que o

\footnotetext{
${ }^{1}$ Doutorando em Ciências Sociais pela Universidade Federal do Rio Grande do Norte (UFRN). Mestre em Ciências Sociais pela UFRN e licenciatura na mesma área pela Universidade Federal de Pernambuco (UFPE). Atualmente desenvolve tese sobre o modernism na poesia de Carlos Drummond de Andrade durante a Era Vargas. E-mail: silvarenato86@gmail.com

${ }^{2}$ Romance vencedor dos prêmios Troféu APCA e Prêmio Machado de Assis de Melhor Romance de 2001.
} 
ELES ERAM MUITOS RUFFATOS/CAVALOS: A CIDADE DE SÃO PAULO E A EMERGÉNCIA

DE UM ESCRITOR A PARTIR DO ROMANCE ELES ERAM MUITOS CAVALOS

Renato Kleibson da Silva

protagonista era o próprio cortiço, sem mencionar que o Brasil ainda não era uma sociedade de classes, mas em formação capitalista, recém-saída de um sistema escravagista.

Para além de $O$ cortiço e os romances, contos e crônicas do escritor mineiro radicado em São Paulo, Roniwalter Jatobá (Campanário, 1949), premiado autor que se notabilizou em retratar o operariado paulista, a literatura brasileira, em grande medida, aborda os segmentos médios da sociedade brasileira, o imigrante nordestino vítima das intempéries naturais ou dos desmandos sociopolíticos da região (parte significativa da literatura Regionalista) ou ainda o lumpemproletariado urbano que vive às margens dos destinos da nação. Como exemplo destacado desse último tipo de produção, está a obra do escritor João Antônio (São Paulo, 1937-1996).

\section{ELES ERAM MUITOS RUFFATOS/CAVALOS OU COMO A TRAJETÓRIA DE UM ESCRITOR SINTETIZA O PERFIL DOS SEUS PERSONAGENS}

Luiz Ruffato é um escritor cuja biografia é destoante da maioria dos ficcionistas brasileiros, eminentemente oriundos da classe média. Filho de um pipoqueiro de Cataguases, interior de Minas, L. Ruffato fora pipoqueiro, caixa de boteco, balconista, operário têxtil, torneiro mecânico, gerente de lanchonete, dentre outras profissões subalternas ${ }^{3}$. Após concluir o curso de jornalismo na Universidade Federal de Juiz de Fora (1984) e trabalhar em diversas redações no interior de Minas, ele chegou a São Paulo em 1990, sendo logo admitido no Jornal da Tarde. No periódico, ele trabalhou até 2003, quando decidiu se afastar do jornalismo e apostar na carreira como escritor (PARDO, 2007).

Fez parte da primeira geração de escritores do Brasil que viveu inteiramente da escrita. Representante de uma pequena "casta", diga-se de passagem, mas em um país onde a "profissão" de escritor era até então prática secundária ou atividade de fim de semana, a crescente profissionalização do escritor no Brasil provou que as festas e

${ }^{3}$ Disponível em: <http://oglobo.globo.com/cultura/viver-de-literatura-9777435> Acesso em: 25 set. 2015. 


\section{ELES ERAM MUITOS RUFFATOS/CAVALOS: A CIDADE DE SÃO PAULO E A EMERGÉNCIA}

DE UM ESCRITOR A PARTIR DO ROMANCE ELES ERAM MUITOS CAVALOS

Renato Kleibson da Silva

os festivais literários, as bienais e feiras do livro, as conferências remuneradas, um expansivo interesse da literatura brasileira pelo mundo, a racionalização do mercado editorial, dentre outros fatores, tornaram a profissão de escritor viável. Desse modo, passou a não ser mais atividade de "mandarins", de profissionais liberais ou passatempo da alta burguesia.

Com EEMC, Luiz Ruffato ganhou notabilidade no interior do campo literário brasileiro e a partir de então começou a ser um dos ficcionistas mais traduzidos no exterior, especialmente após as publicações dos volumes de Inferno Provisório. Esse capital simbólico (BOURDIEU, 2002) Ihe conferiu o discurso ${ }^{4}$ de abertura da maior feira literária do mundo: a Feira Internacional do Livro de Frankfurt (Alemanha), em 2013, cujo homenageado era o Brasil. Na ocasião, L. Ruffato proferiu um polêmico discurso sobre a história do Brasil, o que causou desconforto tanto no campo literário quanto na classe dirigente que estava presente na plateia.

Em relação a $E E M C$, o romance não inova apenas no cerne de sua temática, a vida do proletariado paulista, mas, sobretudo, na forma como são contadas as experiências (68 quadros que transformam a vida das personagens em um grande mosaico em dia na capital paulista) de vida desse estrato social marginalizado, não apenas da ficção brasileira, como também do protagonismo político do país.

Nesse sentido, EEMC tem grande influência dos romances experimentais brasileiros da década de 1970, gênero que L. Ruffato conhece bem porque participara durante a referente década do grupo/movimento estudantil (1979-1985) político e cultural chamado "Abre Alas", em Juiz de Fora. Esse envolvimento conferiu-lhe acesso às obras de vanguarda daquele período, especialmente, à produção poética via mimeógrafo (PARDO, 2007).

Não é demais lembrarmos que é dos anos 1970 o polêmico romance de lgnácio Loyola Brandão (Araraquara, 1936), Zero (1975), o qual lembra bastante a estrutura de EEMC: o recorte, os fragmentos, o fluxo de consciência e a narrativa modular. Foi Loyola Brandão quem escreveu a contracapa do primeiro (considerado) livro de contos

\footnotetext{
${ }^{4}$ Disponível em: <https://www.youtube.com/watch?v=tsqcziX5_6E> Acesso em: 25 set. 2015.
} 


\section{ELES ERAM MUITOS RUFFATOS/CAVALOS: A CIDADE DE SÃO PAULO E A EMERGÉNCIA}

DE UM ESCRITOR A PARTIR DO ROMANCE ELES ERAM MUITOS CAVALOS

Renato Kleibson da Silva

de L. Ruffato, Histórias de remorsos e rancores ${ }^{5}$ (1998), o que configura um conhecimento mútuo da obra dos dois escritores, além da chancela ao campo literário que um gesto como esse conferiu a L. Ruffato. No tocante a esse feito, a sociologia bourdieusiana chama de "instância de consagração" (BOURDIEU, 2002), isto é, quando um escritor consagrado no campo (Loyola Brandão) apresenta um iniciante (L. Ruffato).

\section{O OLHAR/CORPO DE ELES ERAM MUITOS CAVALOS}

No que tange a $E E M C$, tudo indica que o romance antecipa a ascensão de um ex-metalúrgico do ABC paulista, Luiz Inácio Lula da Silva (mais um Luiz), que, meses depois do lançamento do livro, assumiria a presidência da república, em 2002. Outro dado: o romance antecipa a euforia do fim da era FHC e início do Lulismo, porém, sem nenhum tom exultante ou ufanista, porque consegue captar a gênese do "precariado" (precarização dos postos de trabalho da baixa classe média) que iria se consolidar nos anos Lula/Dilma, dimensão que as ciências sociais passam a constatar apenas no final da primeira década do novo milênio.

Com EEMC, L. Ruffato segue a trajetória estética da Teoria Crítica, sobretudo nas obras de Theodor Adorno, que acreditava que o social na obra de arte não está em seu conteúdo, mas em sua forma. O romance de L. Ruffato corrobora essa tese no que tange ao não didatismo ou caricatura, que historicamente - em nossa prosa - retratou o pobre (leia-se qualquer minoria social) como um sujeito destituído de protagonismo e, em especial, de subjetividade autônoma. Ou seja, os pobres sempre foram reproduzidos com sua linguagem "pouco sofisticada" (incorreções gramaticais), repleta de lugares-comuns no que se refere à sua sintaxe, seja verbal, seja corporal.

Nesse sentido, EEMC rompe o terra a terra da ficção brasileira que historicamente apresentou o pobre ora como o sertanejo (ou caipira) ignorante e espoliado pelas estruturas sociais, ora o pobre urbano como alegre e alienado de sua condição social. O livro consegue esse efeito por sua peculiar inovação formal na

\footnotetext{
${ }^{5}$ Livro vencedor do prêmio Casa de las Américas, de 1997.
} 


\section{ELES ERAM MUITOS RUFFATOS/CAVALOS: A CIDADE DE SÃO PAULO E A EMERGÉNCIA}

DE UM ESCRITOR A PARTIR DO ROMANCE ELES ERAM MUITOS CAVALOS

Renato Kleibson da Silva

narrativa - sem nenhuma concessão ao leitor e, principalmente, ao grosso dos personagens que são trazidos à tona em suas experiências mais comezinhas em um dia na vida da grande metrópole indiferente, São Paulo.

Dessa maneira, os personagens do livro de L. Ruffato ganham uma massa de complexidade que lembra muito o ex-funcionário da Fazenda São Bernardo (no romance homônimo de Graciliano Ramos), Paulo Honório, que, longe dos clichês por sua vida pregressa, entra para a história da literatura brasileira como um dos personagens mais bem acabados de nossa prosa por conseguir unir esmero e rigor na narração em primeira pessoa e por fugir da conveniente tese da reprodução social de um sujeito que ascende economicamente.

Seria uma explicação pouco sofisticada tentar explicar as inovações formais e o impacto que EEMC causou no campo literário brasileiro simplesmente fazendo um cotejo com a trajetória de vida do autor. Por esse motivo, tentaremos realizar uma síntese entre a biografia de L. Ruffato e a própria configuração do campo literário brasileiro na virada para o século XXI, quando o livro foi publicado.

De certa forma, EEMC narra as trajetórias dos sujeitos cujas biografias são similares a de L. Ruffato. Nesse momento, tanto o protagonismo das personagens quanto a ascensão do próprio Ruffato dentro do campo literário brasileiro seriam incipientes sem o cotejo com a própria mudança no regaço da economia do país. Não devemos deixar de registrar o crescente desenvolvimento das relações profissionais entre o escritor e o editor e, acima de tudo, uma maior organicidade no tripé autor, obra e público no Brasil dos anos 1990. Grosso modo, EEMC seria a sinédoque de uma classe social (pequena burguesia) em franca ascensão tanto em sua composição formal - fragmento - quanto no interior das ações de suas personagens inseridas na batalha pela sobrevivência na grande cidade.

Foi esse o cenário que L. Ruffato encontrou em São Paulo durante o período que antecedeu EEMC: a euforia do Plano Real, com o câmbio e a inflação controlados, com a taxa de desemprego em níveis razoáveis. Nesse contexto, São Paulo apresentou-se não apenas como a capital da solidão, mas também como a capital da vertigem, 


\section{ELES ERAM MUITOS RUFFATOS/CAVALOS: A CIDADE DE SÃO PAULO E A EMERGÉNCIA} DE UM ESCRITOR A PARTIR DO ROMANCE ELES ERAM MUITOS CAVALOS

Renato Kleibson da Silva

segundo o par de adjetivos criados pelo jornalista Roberto Pompeu de Toledo para se referir ao estado de espírito reinante na capital paulista. Os personagens do livro de L. Ruffato oscilam no movimento pendular entre solidão e vertigem.

A São Paulo retratada em EEMC não é apenas a cidade que não está interessada em saber o sobrenome do forasteiro - como diz o próprio L. Ruffato quando chegou à cidade -, tampouco não é a cidade "Eldorado brasileiro"; "locomotiva nacional" ou de toda sorte de nomenclaturas ufanistas, ela é um lugar hostil para quem está sobre seu chão e sob seu céu. Trata-se de uma cidade fruto de um projeto urbano que isola seus moradores; de um projeto de moradia guetificado; de um projeto econômico centralizador de renda; de um projeto cujo ritmo de vida é acachapante. Enfim, uma cidade erigida em um estranho paradoxo: terra da oportunidade que não permite chauvinismos nas representações artísticas que lhe fazem referência.

Não é exagero falar que a cidade de São Paulo é o personagem principal de $E E M C$, a qual é retratada por uma consciência arguta, não somente pelas experiências profissionais pregressas do autor, ou de seu trabalho na redação do Jornal da Tarde atuante na mesma cidade, mas, sobretudo, pela particularidade de um olhar/corpo "estranho" (estrangeiro) na metrópole recém-conhecida. É o olhar/corpo de quem experimenta a multidão sem fazer parte dela. É o olhar/corpo anônimo do sujeito imerso na vertigem metropolitana sem chamar a atenção, porque seu compromisso com a escrita é ético e estético - foge dos lugares-comuns sobre os tipos urbanos e sobre a cidade de São Paulo, assim como um flâneur foge dos "holofotes" que guiam as multidões. É o olhar/corpo que recebe toda a plêiade de estímulos sensórios/motores sem se embrutecer devido ao excesso, pelo contrário, esse olhar/corpo "estranho" devolve tudo à escrita, acionando o dispositivo que liga estética à ética.

O sociólogo alemão George Simmel, em artigo de 1904, "A metrópole e a vida mental" (VELHO, 1968), aponta que a vida metropolitana gera uma aceleração mental para quem nela vive; por conseguinte, essa vida mental nervosa cria uma postura blasé (apática), porque a soma de inúmeros estímulos diariamente na consciência leva à indiferença frente aos acontecimentos e fenômenos do dia a dia. Ao que tudo indica, o 
embotamento oriundo da aceleração da vida mental não chegou ao narrador "onisciente" de EEMC. A narrativa do livro não é apática, pelo contrário, ela consegue sintonizar (tal qual um dial de FM) múltiplas experiências da cidade com mais de 11 milhões de habitantes. Ainda, é capaz de captar de maneira crível, uma vez que sua força não está na mensagem (conteúdo), mas no meio (forma) como a mensagem é transmitida. Para exemplificar, segue um trecho do livro:

Comecei a ouvir o maior tiroteio pensei em fugir mas ainda corria o risco de ter o carro roubado já pensou? aí tirei a chave da ignição deitei na poltrona de bruços um medo de morrer ali sozinha e então aconteceu uma coisa engraçada parece que eu desmaiei viajei no tempo sei lá me vi de novo mocinha com meus colegas do grupo-de-jovens numa excursão nem imagino pra onde e alguém tocava violão e cantávamos e ríamos e aí começaram a buzinar atrás de mim e assustada dei um pulo liguei o carro engatei a primeira e vi os soldados na calçada arrastando pelas pernas dois sujeitos ensanguentados deviam estar mortos já e vários outros sentados na guia só de cuecas mãos na nuca parecia cena de filme americano (RUFFATO, 2013, p. 27).

O fluxo de consciência presente na citação não reflete apenas o momento limite vivido pela personagem em meio a um tiroteio, mas também nos leva a experiências anteriores na vida dela, numa imagem semi-idílica de um passado comum com um grupo de amigos; de repente, ela volta à "realidade" da cidade, em que a polícia esfola seres humanos em práticas tão corriqueiras, como "cena de filme americano". Em uma palavra: o olhar/corpo do narrador não se deixa levar pelo fluxo, de modo que a austeridade e o rigor da escrita controlam o fluir e o fruir narrativo.

$E E M C$ é repleto de fluxos de consciência, artifício narrativo muito presente na literatura de James Joyce, Virginia Woolf e William Faulkner em meados do século XX, período das vanguardas artísticas e do impacto da psicanálise como narrativa inovadora para o entendimento da consciência fruto da vida burguesa. Visto em retrospectiva, o recurso ao fluxo de consciência realizado pelos três escritores citados há pouco revela muito mais das sociedades contemporâneas - desamparadas de 
grandes narrativas para Ihes guiarem, como, por exemplo, a psicanálise, o marxismo, o fordismo etc. - do que das do século XX.

Nesse ponto, os fluxos de consciência de EEMC destoam dos romances do século XX, tendo em vista que a São Paulo presente na ficção é um lugar onde tudo se fantasmagoriza, isto é, tudo se convulsiona e ganha ribalta frente à narrativa, como se o poder de transformar tudo em mercadoria no capitalismo industrial chegasse ao paroxismo na era do capital financeiro - tempos destituídos de metanarrativas que legislaram a vida durante o século passado. Parece que no romance de L. Ruffato a cidade e a narrativa ganham forças a partir da desprotagonização do humano, em uma palavra: a desumanização do homem frente à "humanização" das coisas. Podemos constatar essa característica neste trecho:

Um rato, de pé sobre as patinhas traseiras, rilha uma casquinha de pão, observando os companheiros que se espalham nervosos por sobre a imundície, como personagens de um videogame. Outro, mais ousado, experimenta mastigar um pedaço de pano emplastrado de cocô mole, ainda fresco, e, desazado, arranha algo macio e quente, que imediatamente se mexe, assustando-o. No após, refeito, aferra os dentinhos na carne tenra, guincha. Excitado, o bando achega-se, em convulsões (RUFFATO, 2013, p. 24).

Ainda sobre o fluxo de consciência, não devemos nos esquecer de que foi um expediente utilizado de maneira inovadora na canção do Racionais MC's, Tô ouvindo alguém me chamar (1997), que narra as reminiscências de um assaltante moribundo na UTI recapitulando - sedado - como chegara até ali após mais um assalto. A narração é pontuada por um frequencímetro cardíaco. O impacto da canção dá-se, em grande medida, pela experiência formal tanto literária quanto na aparelhagem de K. L. Jay (DJ do Racionais MC's). Grande parte da narrativa de Tô ouvindo alguém me chamar se passa na periferia de São Paulo, assim como várias das histórias de EEMC.

Nessa perspectiva, o disco do Racionais MC's, Sobrevivendo no Inferno (1997), faz coro com a pentalogia de L. Ruffato, Inferno Provisório (a palavra "inferno" encontrase presente nas duas obras), que é uma espécie de "continuação" do EEMC. Em suma, 


\section{ELES ERAM MUITOS RUFFATOS/CAVALOS: A CIDADE DE SÃO PAULO E A EMERGÉNCIA}

DE UM ESCRITOR A PARTIR DO ROMANCE ELES ERAM MUITOS CAVALOS

Renato Kleibson da Silva

tanto o livro quanto o disco estavam mirando um objetivo comum: a experiência limite da vida metropolitana em São Paulo, sendo narrada como o único meio que torna uma obra de arte para além das circunstâncias, o rigor formal.

\section{CONCLUSÃO}

A primeira epígrafe que abre o EEMC é assinada por Cecília Meireles, extraída do livro Romanceiro da Inconfidência, e traz os versos: "Eles eram muitos cavalos, I mas ninguém mais sabe os seus nomes, / sua pelagem, sua origem...". Pois bem, esses anônimos perdidos no esquecimento (ou na ignorância blasé da urbe que the vira as costas) geral de seus "nomes" e "pelagem" diante da cidade que os devora diariamente, através de sua solitária vertigem, podem se reconhecer um pouco nesse livro escrito por alguém que já foi um par.

Por fim, EEMC conseguiu antecipar muitos temas que viriam à baila mais de uma década após o seu lançamento, como: o relativo protagonismo, na arena social e política, do pequeno operariado urbano que tomou as ruas nas Jornadas de Junho de 2013, reivindicando, especialmente após a visibilidade dada ao Movimento Passe Livre de São Paulo, entre outros aspectos, uma maior participação nos destinos da nação.

Nesse sentido, como EEMC aponta, essa pequena classe média operária ("precariado" ou "ralé") não possui mais as balizas que orientaram a mesma classe décadas antes: forte presença do discurso de esquerda presente na Igreja Católica (ênfase na Teologia da Libertação) e sindicalismo forte, como nas consequentes greves massivas, sobretudo na região do $A B C$ paulista, contra as espoliações salariais perpetradas pela patronal. Hoje, EEMC assinala que a ideologia que orienta 0 "precariado" não está mais à esquerda, mas sim voltada para um discurso de cunho mais protestante. Ou seja, atomizou os agentes da classe frente à indiferença dos projetos de vida urbanos das grandes cidades brasileiras.

\section{REFERÊNCIAS}


INTER-LEGERE

ELES ERAM MUITOS RUFFATOS/CAVALOS: A CIDADE DE SÃO PAULO E A EMERGÉNCIA

DE UM ESCRITOR A PARTIR DO ROMANCE ELES ERAM MUITOS CAVALOS

Renato Kleibson da Silva

ADORNO, Theodor. Teoria estética. Lisboa: Edições 70, 2008.

BRAGA, Ruy. A política do precariado, do populismo à hegemonia lulista. São Paulo: Boitempo, 2012.

BRANDÃO, I. L. Zero. São Paulo: Global, 2001.

BOURDIEU, Pierre. As regras da arte: gênese e estrutura do campo literário francês. São Paulo: Companhia das Letras, 2002.

BROWN, Mano. Tô ouvindo alguém me chamar. (In: BROWN, Mano. Sobrevivendo no Inferno. São Paulo: Cosa Nostra, 1997. 1 compact disc).

HARRISON, M. I. (Org.). Uma cidade em camadas: ensaios sobre o romance Eles eram muitos cavalos, de Luiz Ruffato. São Paulo: Horizonte, 2007.

MEIRELLES, Cecília. Romanceiro da Inconfidência. Porto Alegre: L\&PM, 2008.

POMPEU, Roberto. São Paulo: capital solidão. São Paulo: Objetiva, 2003.

POMPEU, Roberto. São Paulo: capital vertigem. São Paulo: Objetiva, 2015.

RAMOS, Graciliano. São Bernardo. Rio de Janeiro: Record, 2003.

RUFFATO, Luiz. Eles eram muitos cavalos. São Paulo: Companhia das Letras, 2013.

SOUZA, Jessé. A ralé brasileira, quem é e como vive. Belo Horizonte: Editora da UFMG, 2009.

VELHO, Otávio (Org.). O fenômeno urbano. Rio de Janeiro: Jorge Zahar, 1967. 